\title{
PENGARUH FASILITAS DAN KUALITAS PELAYANAN TERHADAP KEPUASAN PENGGUNA GUDANG KOMODITI SISTEM RESI GUDANG KABUPATEN BOJONEGORO
}

\author{
Endang $^{1}$, Sugiyanto ${ }^{2}$ \\ Prodi Ekonomi Pembangunan, Fakultas Ekonomi, Universitas Bojonegoro ${ }^{1}$ \\ Prodi Agribisnis, Fakultas Pertanian, Universitas Bojonegoro ${ }^{2}$ \\ endangse022@gmail.com
}

\begin{abstract}
ABSTRAK
Tujuan dari penelitian yang dilakukan adalah untuk mengetahui pengaruh parsial fasilitas dan kualitas pelayanan terhadap Kepuasan pengguna Gudang Komoditi Sistem Resi Gudang Kabupaten Bojonegoro dan untuk mengetahui pengaruh simultan fasilitas dan kualitas pelayanan terhadap Kepuasan pengguna gudang komoditi Sistem Resi Gudang Kabupaten Bojonegoro. Metode pengumpulan data dalam penelitian ini adalah menggunakan data primer dan data skunder. Teknik analisa menggunakan analisis regresi linier berganda. Hasil analisis diperoleh fasilitas berpengaruh positif terhadap kepuasan pengguna gudang Komoditi Sistem Resi Gudang Kabupaten Bojonegoro. Kualitas pelayanan berpengaruh positif terhadap kepuasan pengguna gudang Komoditi Sistem Resi Gudang Kabupaten Bojonegoro. Hasil uji $\mathrm{F}$ diperoleh nilai $\mathrm{F}$ hitung sebesar 34,885 dengan tingkat signifikan sebesar 0,000 yang berarti bahwa fasilitas dan kualitas pelayanan secara simultan berpengaruh positif dan signifikan terhadap Kepuasan pengguna gudang komoditi Sistem Resi Gudang Dander Kabupaten Bojonegoro.
\end{abstract}

Kata Kunci: Fasilitas, Kualitas Pelayanan, Kepuasan, Gudang

\section{PENDAHULUAN}

Industri yang bergerak di bidang jasa salah satunya memiliki prioritas utama pada kepuasan ke pelanggan. Persoalan kepuasan konsumen merupakan suatu hal yang sangat penting bagi perusahaan yang bergerak dibidang jasa. Gudang Komoditi Sistem Resi Gudang Kabupaten Bojonegoro mulai beroperasi pada tahun 2013. Gudang Komoditi Sistem Resi Gudang Kabupaten Bojonegoro terletak di desa Ngraseh Kecamatan Dander Kabupaten Bojonegoro dengan pertimbangan : 1) Terletak di sentra produksi gabah/beras/jagung; 2) Di dekat atau di pinggir jalan kelas I; 3) Lokasi gudang SRG aman dari banjir dan bahaya longsor; 4) Jauh dari pabrik atau gudang bahan kimia berbahaya, Stasiun Pengisian Bahan Bakar Umum dan/atau tempat pembuangan sampah/limbah kimia; 5) Bangunan gudang terpisah dengan bangunan di sekitarnya; 6) Diupayakan ada lahan cadangan untuk penambahan fasilitas dan pengembangan usaha di masa mendatang; 7) Tidak terletak pada bekas tempat pembuangan sampah dan bekas 
pabrik bahan kimia; 8) Mendapat persetujuan dari BAPPEBTI.

Gudang Komoditi Sistem Resi Gudang Kabupaten Bojonegoro diharapkan oleh pemerintah Kabupaten Bojonegoro bisa dimanfaatkan oleh petani dan pelaku usaha salah satunya adalah untuk memperoleh harga jual yang lebih baik, dengan cara menyimpan hasil komoditi di Gudang Komoditi Sistem Resi Gudang Ngraseh Dander Kabupaten Bojonegoro saat panen raya yang pada umumnya harga rendah dan kemudian menjualnya pada saat harga tinggi. Gudang Komoditi Sistem Resi Gudang Kabupaten Bojonegoro bergerak di bidang jasa salah satunya memiliki prioritas utama pada kepuasan ke pelanggan. Persoalan kepuasan konsumen merupakan suatu hal yang sangat penting bagi perusahaan yang bergerak dibidang jasa. Pelanggan diharapkan bukan hanya memperoleh layanan yang dibutuhkan saja, tetapi memperoleh layanan yang melebihi harapannya. Kepuasan konsumen merupakan suatu target atau sasaran yang harus dicapai oleh setiap perusahaan dan untuk mencapai kepuasan konsumen dapat dilihat dari fasilitas dan kualitas pelayanan yang diberikan. Tujuan dari penelitian adalah Untuk mengetahui pengaruh parsial fasilitas dan kualitas pelayanan terhadap Kepuasan Pengguna Gudang Komoditi Sistem Resi Gudang Kabupaten
Bojonegoro dan untuk mengetahui pengaruh simultan fasilitas dan kualitas pelayanan terhadap kepuasan pengguna Gudang Komoditi Sistem Resi Gudang Kabupaten Bojonegoro.

\section{KAJIAN PUSTAKA}

\section{Gudang}

Tompkins \& Tanchoco, 1996 dalam Heldy Juliana, Naniek Utami Handayani, 2016; Gudang merupakan tempat penyimpanan material yang diperlukan untuk proses produksi, material tersebut akan terus disimpan hingga siap diproses sesuai dengan jadwal produksi atau order konsumen. Adapun tujuan dari kegiatan penyimpanan material adalah : a) Untuk menyeimbangkan antara kemampuan produksi dengan demand konsumen; b) Untuk memberikan pelayanan yang spesifik; c) dan tujuan lainnya adalah untuk menambah nilai pada suatu produk. Aktivitas yang umumnya dilakukan berkaitan dengan penyimpanan material dalam gudang, adalah receiving, prepacking, put-away, storage, order picking, packaging, sortation and accumulation, packing and shipping.

Heldy Juliana, Naniek Utami Handayani, 2016; Gudang merupakan tempat penyimpanan material yang diperlukan untuk proses produksi, material tersebut akan terus disimpan hingga siap 
diproses sesuai dengan jadwal produksi atau order konsumen. Tujuan suatu kegiatan penyimpanan material antara lain : 1) Untuk menyeimbangkan antara kemampuan suatu produksi dengan demand konsumen; 2) Untuk memberikan pelayanan kepada pelanggan dengan lebih spesifik; 3) Tujuan yang berikutnya adalah untuk menambah nilai pada suatu produk.

Menurut Yunarto dan Santika, 2005 dalam Hery Hamdi Azwir, Oktavia Patrian, 2017 terdapat beberapa tipe gudang seperti: retail warehouse, central warehouse, manufacturing warehouse, dan distribution warehouse. Gudang memiliki fungsi sebagai tempat untuk menyimpan barang mentah, barang setengah jadi, dan barang yang siap untuk dipasarkan ataupun alat pekerja.

\section{Fasilitas}

Menurut Moenir (2001: 119) dalam Nawawi dan Puspitowati (2015); menyatakan bahwa "fasilitas adalah segala jenis peralatan, perlengkapan kerja dan pelayanan yang berfungsi sebagai alat utama/pembantu dalam melaksanakan pekerjaan, dan juga sosial dalam rangka kepentingan orang-orang yang sedang berhubungan dengan organisasi kerja itu atau segala sesuatu yang digunakan, dipakai, ditempati, dan dinikmati oleh orang pengguna.”
Kotler, 2009: 45 dalam Indra Lutfi Sofyan, Ari Pradhanawati \& Hari Susanta Nugraha (2013); Fasilitas merupakan segala sesuatu yang sengaja disediakan oleh penyedia jasa untuk dipakai serta dinikmati oleh konsumen yang bertujuan memberikan tingkat kepuasan yang maksimal. Fasilitas merupakan segala sesutau yang bersifat peralatan fisik yang disediakan oleh pihak penjual jasa untuk mendukung kenyamanan konsumen.

Lupiyoadi, (2008: 148) dalam Indra Lutfi Sofyan, Ari Pradhanawati \& Hari Susanta Nugraha (2013); Fasilitas merupakan penampilan, kemampuan sarana prasarana dan keadaan lingkungan sekitarnya dalam menunjukkan eksistensinya kepada eksternal yang meliputi fasilitas fisik (gedung) perlengkapan dan peralatan. Yang termasuk fasilitas dapat berupa alat, bendabenda, perlengkapan, uang, ruang tempat kerja.

\section{Kualiatas Pelayanan}

Setiawan (2014:14) dalam Jarliyah Harfika ， Nadiya Abdullah (2017); "Kualitas pelayanan merupakan hal yang mutlak yang harus dimiliki oleh perusahaan atau instansi yang menawarkan jasa, karena dengan kualitas pelayanan kepada konsumen, perusahaan atau instansi 
dapat mengukur tingkat kinerja yang telah dicapai".

Dalam salah satu studi mengenai SERVQUAL menurut Parasuraman, et al dalam Lupiyoadi (2008:182) dalam Indra Lutfi Sofyan, Ari Pradhanawati \& Hari Susanta Nugraha (2013), terdapat lima dimensi SERVQUAL sebagai berikut: (1) Tangible (Berwujud), yaitu kemampuan perusahaan untuk memperlihatkan eksistensinya kepada pihak luar atau pihak eksternal. Penampilan dan kemampuan yang dimiliki perusahaan yang berupa sarana dan prasarana fisik yang dapat diandalkan dan kondisi lingkungan sekitarnya merupakan bukti nyata dari pelayanan yang diberikan oleh pemberi jasa. Hal tersebut meliputi fasilitas fisik seperti gedung, gudang, dan lain sebagainya, peralatan dan perlengkapan atau teknologi yang dipergunakan oleh perusahaan, serta penampilan, pengetahuan dan kecakapan pegawainya. (2) Reliability (Keandalan), yaitu kemampuan perusahaan untuk memberikan pelayanan sesuai yang dijanjikan secara akurat dan terpercaya. Kinerja harus sesuai dengan harapan pelanggan yang berarti ketepatan waktu, pelayanan yang sama untuk semua pelanggan tanpa kesalahan, sikap yang simpatik, dan dengan akurasi yang tinggi. (3) Responsiveness (Ketanggapan), yaitu suatu kebijakan untuk membantu dan memberikan pelayanan yang cepat (responsif) dan tepat kepada pelanggan, dengan penyampaian informasi yang jelas. Membuat konsumen menunggu dalam waktu tertentu menyebabkan persepsi yang tidak baik atau negatif dalam kualitas pelayanan. (4) Assurance (Jaminan), yaitu pengetahuan, kesopan santunan, dan kemampuan para pegawai perusahaan untuk menumbuhkan rasa percaya para pelanggan kepada perusahaan. Hal ini meliputi beberapa komponen antara lain communication (komunikasi), credibility (kredibilitas), security (keamanan), competence (kompetensi), dan courtesy (sopan santun). (5) Empati (Emphaty), yaitu memberikan suatu perhatian secara tulus dan yang bersifat individual atau pribadi yang diberikan kepada para pelanggan dengan berupaya memahami keinginan konsumen. Di mana suatu perusahaan diharapkan memiliki pengertian dan pengetahuan tentang pelanggan, memahami kebutuhan pelanggan secara spesifik, serta memiliki waktu pengoperasian yang nyaman bagi pelanggan.

\section{Kepuasan}

Menurut Kotler dan Keller (2008:177) dalam dalam Indra Lutfi Sofyan, Ari Pradhanawati \& Hari Susanta Nugraha (2013); “kepuasan pelanggan 
adalah tingkat perasaan yang di rasakan oleh seseorang atau konsumen setelah membandingkan hasil dari kinerja yang ia rasakan dibandingkan dengan harapannya. Sedangkan menurut Engel, et al dalam Tjiptono (2006:146) kepuasan pelanggan merupakan evaluasi purna beli dimana alternatif yang dipilih sekurang-kurangnya member outcome (hasil) sama atau melampaui harapan pelanggan, sedangkan ketidak puasan timbul apabila hasil yang diperoleh tidak memenuhi harapan pelanggan".

Sudaryono (2016); “Kepuasan adalah hasil dari penilaian konsumen bahwa produk atau jasa pelayanan telah memberikan tingkat kenikmatan dimana tingkat pemenuhan ini bisa lebih atau kurang”. Kepuasan konsumen dapat diartikan sebagai keseluruhan sikap yang ditunjukkan oleh konsumen atas barang dan jasa setelah mereka memperoleh dan menggunakannya.

\section{Kerangka konseptual}

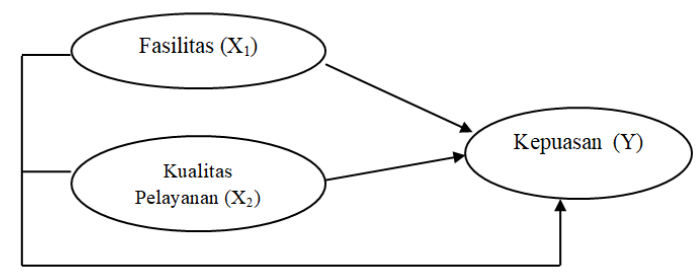

Gambar 1. Kerangka Konseptual

\section{Hipotesis}

1. Fasilitas dan Kualitas Pelayanan secara parsial berpengaruh positif terhadap
Kepuasan pengguna gudang komoditi Sistem Resi Gudang Dander Kabupaten Bojonegoro.

2. Fasilitas dan Kualitas Pelayanan secara simultan berpengaruh positif terhadap Kepuasan pengguna gudang komoditi Sistem Resi Gudang Dander Kabupaten Bojonegoro.

\section{METODE PENELITIAN}

\section{Lokasi Penelitian}

Penelitian ini dilakukan di Gudang Komoditi Sistem Resi Gudang Ngraseh Dander Kabupaten Bojonegoro dengan pertimbangan bahwa Gudang Komoditi Sistem Resi Gudang Kabupaten Bojonegoro bergerak di bidang jasa dan diharapkan oleh pemerintah Kabupaten Bojonegoro bisa dimanfaatkan oleh petani dan pelaku usaha.

\section{Teknik Analisa Data}

\section{Uji Validitas dan Reliabilitas}

Uji validitas digunakan untuk mengukur sah atau valid tidaknya suatu kuesioner (Ghozali, 2001, dalam Endang \& Laily Nur Cholida, 2017). Suatu kuesioner dikatakan sah atau valid jika pertanyaan pada kuesioner tersebut mampu mengungkapkan sesuatu yang akan diukur oleh kuesioner itu. Uji signifikansi dilakukan dengan membandingkan nilai $r$ hitung (nilai Corrected item-Total Correlation pada output Cronbach alpha) 
dengan nilai $r$ tabel untuk degre of freedom $(\mathrm{df})=\mathrm{n}-2(\mathrm{n}$ adalah jumlah sampel $)$.

Pengujian alat pengumpul data yang berikutnya adalah pengujian realibilitas instrument. Uji ini digunakan untuk mengukur suatu kuesioner yang merupakan indikator dari variabel atau konstruk (Ghozali, 2001, dalam Endang \& Laily Nur Cholida, 2017). Kuesioner bisa dikatakan reliabel atau handal apabila jawaban responden atau seseorang terhadap pertanyaan atau pernyataan adalah konsisten atau stabil dari waktu ke waktu. Suatu variabel dikatakan reliabel jika memiliki Cronbach Alpha > 0,60 (Ghozali, 2001, dalam Endang \& Laily Nur Cholida, 2017).

\section{Analisis Regresi Berganda}

Analisis regresi dipergunakan untuk menelaah hubungan anatara dua variabel atau lebih, atau untuk mengetahui bagaimana variasi dari beberapa variabel independen mempengaruhi variabel dependen dalam suatu fenomena yang komplek. Selain itu juga analisis regresi digunakan untuk menguji kebenaran hipotesis yang diajukan dalam penelitian ini. Berikut ini adalah model regresi berganda:

$$
\mathrm{Y}=\mathrm{a}+\mathrm{b}_{1} \mathrm{X}_{1}+\mathrm{b}_{2} \mathrm{X}_{2}+\mathrm{e}
$$

\section{HASIL DAN PEMBAHASAN}

\section{Hasil Uji Validitas}

Tabel 1

Hasil Uji Validitas

\begin{tabular}{|c|c|c|c|}
\hline Item & $\begin{array}{l}\text { Item-Total } \\
\text { Correlation }\end{array}$ & r tabel & Keterangan \\
\hline \multicolumn{4}{|c|}{ Fasilitas (X1) } \\
\hline X.1.1 & 0,777 & 0,279 & Valid \\
\hline X.1.2 & 0,823 & 0,279 & Valid \\
\hline $\mathrm{X} 1.3$ & 0,837 & 0,279 & Valid \\
\hline X.1.4 & 0,761 & 0,279 & Valid \\
\hline $\mathrm{X} .1 .5$ & 0,871 & 0,279 & Valid \\
\hline Item & $\begin{array}{l}\text { Item-Total } \\
\text { Correlation }\end{array}$ & r tabel & Keterangan \\
\hline \multicolumn{4}{|c|}{ Kualitas Pelayanan (X2) } \\
\hline X.2.1 & 0,843 & 0,279 & Valid \\
\hline X.2.2 & 0,845 & 0,279 & Valid \\
\hline X.2.3 & 0,904 & 0,279 & Valid \\
\hline X.2.4 & 0,791 & 0,279 & Valid \\
\hline X.2.5 & 0,908 & 0,279 & Valid \\
\hline \multicolumn{4}{|c|}{ Kepuasan (Y) } \\
\hline Y1 & 0,784 & 0,279 & Valid \\
\hline Y 2 & 0,782 & 0,279 & Valid \\
\hline Y 3 & 0,777 & 0,279 & Valid \\
\hline Y 4 & 0,870 & 0,279 & Valid \\
\hline Y 5 & 0,809 & 0,279 & Valid \\
\hline
\end{tabular}

Sumber : Data primer yang diolah, 2019

Hasil pengujuian validitas item kuesioner menunjukkan bahwa seluruh item pertanyaan dalam setiap variable memiliki Item-Total Correlation > 0,279 maka pertanyaan tersebut valid. Sehingga dapat dikatakan bahwa item angket dapat digunakan untuk mengukur variable yang diteliti. 


\section{Uji Reliabilitas}

Tabel 2

Hasil Uji Reliabilitas

\begin{tabular}{|c|l|c|c|}
\hline No & Variabel & $\begin{array}{c}\text { Cronbach } \\
\text { Alpha }\end{array}$ & Keterangan \\
\hline 1 & Fasilitas (X1) & 0,873 & Reliabel \\
\hline 2 & $\begin{array}{l}\text { Kualitas } \\
\text { Pelayanan (X2) }\end{array}$ & 0,910 & Reliabel \\
\hline 3 & Kepuasan (Y) & 0,862 & Reliabel \\
\hline
\end{tabular}

Sumber : Data primer yang diolah, 2019

Berdasarkan hasil pengujian reliabilitas dengan program SPSS, diketahui nilai koefisien alpha untuk variable Faslitias $\left(\mathrm{X}_{1}\right)$ sebesar 0,873, karena diperoleh nilai koofesien realibitas $>0,60$ atau $\quad 0,873>0,60$, maka dapat disimpulkan bahwa instrument penelitian tersebut dinyatakan reliebel dan dapat dipergunakan sebagai alat pengumpul data. Untuk variable Kualitas Pelayanan $\left(\mathrm{X}_{2}\right)$ nilai koefisien alpha sebesar 0,910 karena diperoleh nilai koofesien realibitas $>0,60$ atau $0,910>0,60$ maka dapat disimpulkan bahwa instrument penelitian tersebut dinyatakan reliebel dan dapat dipergunakan sebagai alat pengumpul data. Nilai koefisien alpha untuk variable Kepuasan (Y) sebesar 0,862, karena diperoleh nilai koofesien realibitas > 0,60 atau 0,862 >0,60, artinya instrument penelitian dinyatakan reliable dan dapat dipergunakan sebagai alat pengumpul data. Dengan demikian nilai koofisien hitung alpha lebih besar dari nilai koofesien realibitas >0,60, maka dapat bahwa instrument penelitian tersebut dinyatakan reliable.

\section{Uji Autokorelasi}

Tabel 3

Hasil Uji Autokorelasi

\begin{tabular}{|c|c|c|c|c|c|}
\hline Model & $\mathrm{R}$ & $\begin{array}{l}\mathrm{R} \\
\text { Square }\end{array}$ & $\begin{array}{l}\text { Adjusted } \\
\text { R Square }\end{array}$ & $\begin{array}{l}\text { Std. } \\
\text { Error of } \\
\text { the } \\
\text { Estimate }\end{array}$ & $\begin{array}{l}\text { Durbi } \\
\text { n- } \\
\text { Wats } \\
\text { on }\end{array}$ \\
\hline 1 & $824^{\mathrm{a}}$ & .679 & 659 & 1.199 & 1.061 \\
\hline
\end{tabular}

Sumber : Data primer yang diolah, 2019

Berdasarkan pada tabel 3, analisis menunjukkan bahwa angka D-W sebesar $+1,061$. Hal ini berarti bahwa model penelitian tidak mempunyai problem autokorelasi.

\section{Uji Heteroskedastisitas}

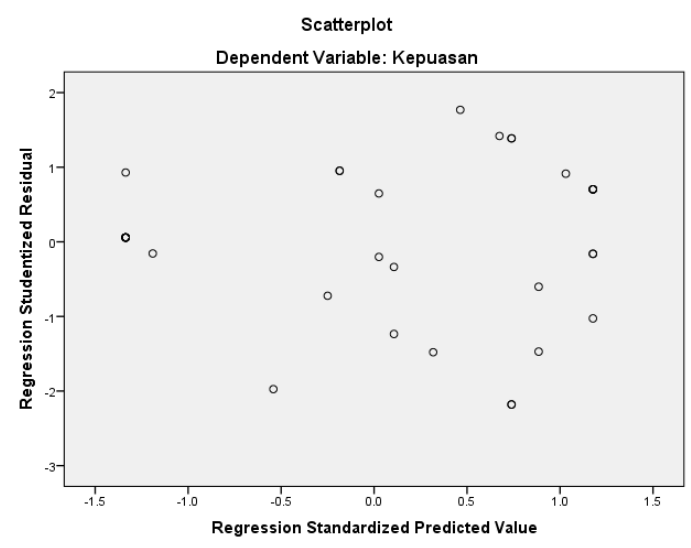

Gambar 2. Scatterplot

Sumber : Data primer yang diolah, 2019

Berdasarkan pada gambar 2, chart diatas terlihat bahwa titik-titik menyebar ke atas dan menyebar di bawah 0 , sehingga dapat disimpulkan tidak terjadi heteroskedastisitas. 


\section{Analisis Regresi Berganda}

Tabel 4

Hasil Uji Regresi

\begin{tabular}{|c|l|l|l|l|l|}
\hline \multirow{2}{*}{ Model } & \multicolumn{2}{|l|}{$\begin{array}{l}\text { Unstandardized } \\
\text { Coefficients }\end{array}$} & $\begin{array}{l}\text { Standardized } \\
\text { Coefficients }\end{array}$ & $\mathrm{t}$ & Sig. \\
\cline { 2 - 7 } & $\mathrm{B}$ & $\begin{array}{l}\text { Std. } \\
\text { Error }\end{array}$ & Beta & & \\
\hline $1 \quad$ (Constant) & 2.922 & 2.402 & & 1.217 & .232 \\
\hline \multicolumn{1}{|c|}{ Fasilitas } & .247 & .140 & .242 & 1.760 & .088 \\
\hline $\begin{array}{l}\text { Kualitas } \\
\text { Pelayanan }\end{array}$ & .604 & .131 & .636 & 4.617 & .000 \\
\hline
\end{tabular}

a. Dependent Variable: Kepuasan

Sumber : Data primer yang diolah, 2019

Bedasarkan hasil analisis regresi pada tabel 4 maka dapat disusun persamaan sebagai berikut:

$\mathrm{Y}=2,922+0,247 \mathrm{X}_{1}+0,604 \mathrm{X}_{2}+\mathrm{e}$

Persamaan regresi tersebut mempunyai arti sebagai berikut;

1. Konstanta sebesar 2,922, artinya bahwa nilai konstanta positif menunjukkan bahwa kepuasan sebesar 2,922 dengan asumsi bahwa variable independent fasilitas $\left(\mathrm{X}_{1}\right)$ dan kualitas pelayanan $\left(\mathrm{X}_{2}\right)$ sama dengan 0 (nol). Bila variable independen naik atau berpengaruh dalam satu satuan, maka variable kepuasan akan naik atau terpenuhi.

2. Koefisien regresi Fasilitas $=0,247$, artinya bahwa koefisien regresi positif sebesar 0,247. Jika Fasilitas ( $\left.\mathrm{X}_{1}\right)$ meningkat sebesar 1 satuan, maka Kepuasan (Y) juga akan meningkat sebesar 0,247 atau 24,7\%. Artinya, jika Fasilitas naik sebesar 0,247 maka kepuasan juga akan meningkat (naik) sebesar 0,247 atau $24,7 \%$.

3. Koefisien regresi Kualitas Pelayanan $=$ 0,604 , artinya bahwa koefisien regresi positif sebesar 0,604. Jika Kualitas Pelayanan $\left(\mathrm{X}_{2}\right)$ meningkat sebesar 1 satuan, maka Kepuasan (Y) juga akan meningkat sebesar 0,604 atau 60,4\%. Artinya, jika Kualitas Pelayanan naik sebesar 0,604 maka kepuasan juga akan meningkat (naik) sebesar 0,604 atau $60,4 \%$.

Pengujian hipotesis yang pertama adalah untuk membuktikan bahwa fasilitas dan kualitas pelayanan secara parsial berpengaruh positif terhadap Kepuasan pengguna gudang komoditi Sistem Resi Gudang Dander Kabupaten Bojonegoro. Berdasarkan tabel 4 hasil uji $\mathrm{t}$ dapat diartikan bahwa:

1. Variable $X_{1}$ (Fasilitas) merupakan variable yang diduga secara parsial berpengaruh positif terhadap kepuasan pengguna gudang komoditi Sistem Resi Gudang Kabupaten Bojonegoro. Berdasarkan nilai perhitungan dengan menggunakan SPSS 23.0 seperti pada tabel 4 diatas nilai $\mathrm{t}$ hitung variable $\mathrm{X}_{1}$ (Fasilitas) sebesar 1,760 dan nilai signifikan sebesar 0,088. Ketentuan pengambilan keputusan hipotesis didasarkan pada besarnya nilai signifikasi. Jika signifikasi lebih kecil 
atau sama dengan $0,05(\leq 0,05)$ maka dikatakan signifikan. Hasil analisis diperoleh nilai signifikasi sebesar 0,088 $>0,05$, maka dapat disimpulkan bahwa fasilitas berpengaruh positif terhadap kepuasan pengguna gudang komoditi Sistem Resi Gudang Kabupaten Bojonegoro tetapi tidak signifikan terhadap kepuasan pengguna gudang komoditi Sistem Resi Gudang Kabupaten Bojonegoro.

2. Variable $\mathrm{X}_{2}$ (Kualitas Pelayanan) merupakan variable yang diduga secara parsial berpengaruh positif terhadap kepuasan pengguna gudang SRG Kabupaten Bojonegoro. Nilai $t$ hitung variable $\quad \mathrm{X}_{2} \quad$ (Kualitas Pelayanan) sebesar 4,617 dengan nilai signifikan sebesar 0,000. Ketentuan pengambilan keputusan hipotesis didasarkan pada besarnya nilai signifikasi. Jika signifikasi lebih kecil atau sama dengan $0,05(\leq 0,05)$ maka dikatakan signifikan. Hasil analisis diperoleh nilai signifikasi sebesar $0,000>0,05$, maka dapat disimpulkan bahwa kualitas pelayanan berpengaruh positif dan signifikan terhadap kepuasan pengguna gudang komoditi Sistem Resi Gudang Kabupaten Bojonegoro.

Pengujian hipotesis kedua, untuk membuktikan bahwa fasilitas dan kualitas pelayanan secara simultan berpengaruh positif terhadap Kepuasan pengguna gudang komoditi Sistem Resi Gudang Dander Kabupaten Bojonegoro digunakan uji F (Anova) sebagaimana dapat dilihat pada tabel berikut:

Tabel 5

Hasil Uji F (Anova ${ }^{\mathrm{a}}$ )
\begin{tabular}{|c|c|c|c|c|c|c|}
\hline \multicolumn{2}{|l|}{ Model } & $\begin{array}{l}\text { Sum of } \\
\text { Squares }\end{array}$ & Df & $\begin{array}{l}\text { Mean } \\
\text { Square }\end{array}$ & F & Sig. \\
\hline 1 & Regression & 100.231 & 2 & 50.115 & 34.885 & $.000^{\mathrm{b}}$ \\
\hline & Residual & 47.408 & 33 & 1.437 & & \\
\hline \multicolumn{2}{|l|}{ Total } & 147.639 & 35 & & & \\
\hline
\end{tabular}
a. Dependent Variable: Kepuasan
b. Predictors: (Constant), KualitasPelayanan, Fasilitas

Sumber : Data primer yang diolah, 2019

Berdasarkan tabel 5, hasil uji $\mathrm{F}$ diperoleh nilai $\mathrm{F}$ hitung sebesar 34,885 dengan tingkat signifikan sebesar 0,000 (lebih kecil dari 0,05) yang berarti hal ini menunjukkan bahwa fasilitas dan kualitas pelayanan secara simultan berpengaruh positif dan signifikan terhadap Kepuasan pengguna gudang komoditi Sistem Resi Gudang Dander Kabupaten Bojonegoro.

Untuk mengetahui kontribusi pengaruh variabel fasilitas dan kualitas pelayanan terhadap kepuasan pengguna gudang komoditi Sistem Resi Gudang Dander Kabupaten Bojonegoro digunakan analisis koefisien determinasi sebagaimana dapat dilihat pada tabel 6 berikut:

Tabel 6 Model Summary

\begin{tabular}{|l|l|l|l|l|}
\hline Model & $\mathrm{R}$ & R Square & $\begin{array}{l}\text { Adjusted R } \\
\text { Square }\end{array}$ & $\begin{array}{l}\text { Std. Error of } \\
\text { the Estimate }\end{array}$ \\
\hline 1 & $.824^{\mathrm{a}}$ & .679 & .659 & 1.199 \\
\hline \multicolumn{4}{|l|}{ a. Predictors: (Constant), KualitasPelayanan, Fasilitas } \\
\hline
\end{tabular}

Sumber : Data primer yang diolah, 2019 
Output dari tabel 6 , tersebut nilai $\mathrm{R}$ Square adalah sebesar 0,679 yang berarti bahwa $67,9 \%$ kepuasan pengguna gudang komoditi Sistem Resi Gudang Dander Kabupaten Bojonegoro dipengaruhi oleh variable fasilitas dan kualitas pelayanan. Sedangkan sisanya sebesar $32,1 \%$ dipengaruhi oleh variable lain diluar fasilitas dan kualitas pelayanan.

\section{KESIMPULAN}

Berdasarkan hasil analisa yang dilakukan maka dapat ditarik kesimpulan dalam penelitian ini adalah fasilitas berpengaruh positif terhadap kepuasan pengguna gudang komoditi Sistem Resi Gudang Kabupaten Bojonegoro. Kualitas pelayanan berpengaruh positif terhadap kepuasan pengguna gudang komoditi Sistem Resi Gudang Kabupaten Bojonegoro. Fasilitas dan Kualitas Pelayanan secara simultan berpengaruh positif terhadap Kepuasan pengguna gudang komoditi Sistem Resi Gudang Dander Kabupaten Bojonegoro.

Bagi penelitian selanjutnya dapat menggunakan variable yang berbeda dari penelitian ini sehingga dapat menunjukkan hasil yang berbeda. Bagi pemerintah Kabupaten Bojonegoro dan pimpinan gudang komoditi SRG dander Kabupaten Bojonegoro diharapkan dapat meningkatkan fasilitas dan kualitas pelayanan agar dapat meningkatkan kepuasan pengguna gudang komoditi SRG dander Kabupaten Bojonegoro karena sesuai dengan harapan dari pemerintah Kabupaten Bojonegoro adalah gudang komoditi Sistem Resi Gudang bisa digunakan oleh petani untuk menyimpan hasil komoditinya pada saat panen raya karena pada umumnya harga rendah. Dengan cara menyimpan komoditi di gudang saat panen raya kemudian menjualnya ketika harga tinggi.

\section{DAFTAR PUSTAKA}

Dinas Perindustrian Dan Perdagangan Kabupaten Bojonegoro, Oktober 2013; SISTEM RESI GUDANG (SRG) Solusi Permasalahan Petani Bojonegoro.

Tompkins, J. A., White, J. A., dan Tanchoco, J. M. (1996). Facilities Planning (Fourth ed.). USA: John Wiley \& Sons.

H.I. Yunarto dan M.G. Santika. Business Concept Implementation Series In Inventory Management. Jakarta: Elex Media, 2005.

Heldy Juliana, Naniek Utami Handayani, 2016; Peningkatan Kapasitas Gudang Dengan Perancangan Layout Menggunakan Metode 
Class-Based Storage. Jurnal Teknik Industri, Vol. XI, No. 2, Mei 2016.

Hery Hamdi Azwir, Oktavia Patrian, 2017; Perbaikan Pengelolaan Pergudangan Melalui Penerapan Sistem Informasi Pergudangan di $C V$. $A B B$. JURNAL OPTIMASI SISTEM INDUSTRI - VOL. 16 NO. 01 (2017) 010-024. ISSN (Print) 2088-4842. Universitas Presiden, Kota Jababeka, Cikarang, Bekasi, 17550, Indonesia.

Moenir, H.A.S. (2001) Manajemen Pelayanan Umum di Indonesia. Jakarta, PT. Bumi Aksara.

M. Tony Nawawi \& Ida Puspitowati, 2015; Pengaruh Kualitas Pelayanan Dan Fasilitas Perpustakaan Sebagai Prediktor Terhadap Kepuasan Civitas Akademika Fakultas Ekonomi Universitas

Tarumanagara Di Jakarta. Jurnal Ekonomi/Volume XX, No. 02, Juli 2015: 320-334.

Kotler, Philip. 2009. Manajemen Pemasaran, Jilid 2, Edisi 13. Alih Bahasa Benyamin Molan. Jakarta: Prehallindo.

Indra Lutfi Sofyan, Ari Pradhanawati \& Hari Susanta Nugraha, 2013; Pengaruh Fasilitas an Kualitas Pelayanan Terhadap Loyalitas,
Melalui Kepuasan Konsumen Sebagai Variabel Intervening pada Star Clean Car Wash Semarang. DIPONEGORO JOURNAL OF SOCIAL AND POLITIC Tahun 2013, Hal. 1-12 http://ejournals1. undip.ac.id/index.php/

Lupiyoadi, Rambat, dan Hamdani, A. 2008. Manajemen Pemasaran Jasa. Jakarta: Salemba Empat.

Setiawan, Ryan Agung. (2014). “Analisis Pengaruh Promosi Dan Kualitas Pelayanan Terhadap Kepuasaan Pelanggan (Studi Kasus : “Waroeng Spesial).

Jarliyah Harfika , Nadiya Abdullah, 2017; Pengaruh Kualitas Pelayanan Dan Fasilitas Terhadap Kepuasan Pasien Pada Rumah Sakit Umum Kabupaten Aceh Barat Daya. Jurnal Balance Vol. XIV No. 1 | Januari 2017 : 44-56.

Tjiptono, Fandy. 2006. Manajemen Jasa. Yogyakarta: Andi

Sudaryono, (2016). Manajemen Pemasaran Teori \& Implementasi Ed. I . - Yogyakarta : ANDI

Kotler, P., \& Keller, K. L. (2016). Marketing Management. $15^{\text {th }}$ Edition. Pearson Education.

Ali Fathoni, Hery Suprapto, 2016; Pengaruh Kualitas Pelayanan, Harga Dan Fasilitas Terhadap 
Kepuasan Pelanggan Pada Rumah Sakit Islam Nashrul Ummah Lamongan. Jurnal E K B I S / V o l . XVI/No. 2 Edisisepte mb e $\quad r \quad 2 \quad 0 \quad 1 \quad 6$ Fakultas Ekonomi Universitas Islam Lamongan.

Sujarweni, V. Wiratna (2015). Metodologi Penelitian Bisnis \& Ekonomi. Cetakan Pertama. Yogyakarta: PUSTAKA BARU PRESS.

Endang \& Laily Nur Cholida, 2017; Pengaruh Fasilitas Dan Kualitas Pelayanan Terhadap Kepuasan Penumpang Di Terminal Rajekwesi Bojonegoro. Jural TeknikA Vol 9 No 2 September 2017, $911-915$. ISSN No. 2085 - 0859.

Sugiyono (2010). Metode Penelitian Pendidikan. Bandung: Alfabeta.

Uma Sekaran. 2006. Metode Penelitian Bisnis. Jakarta : Salemba Empat.

Fauzi, Mochamad (2009). Metode Penelitian Kuantitatif Sebuah Pengantar. Cet. 1 - Semarang: 